\title{
The use of the international classification of functioning, disability and health in an interactive perspective: the assessment and intervention of students' additional support needs in Portugal
}

\author{
Monica Silveira-Maia ${ }^{a}$, Pedro Lopes-dos-Santos ${ }^{b}$, Manuela Sanches-Ferreira ${ }^{a}$ (D), Silvia Alves ${ }^{a}$ and \\ Carla Silveira-Maiac \\ aDepartment of Special Education and Inclusion, School of Education, Porto Polytechnic Institute, Porto, Portugal; bschool of Psychology and \\ Education, University of Porto, Porto, Portugal; ' CDepartment of Communication and Arts, University of Aveiro, Aveiro, Portugal
}

\begin{abstract}
Purpose: Evaluating the influence of person-environment interactions on students' performance is a fundamental requirement for planning individualized educational interventions. Such understanding grounded the use of the International Classification of Functioning, Disability and Health as a reference framework to support special needs assessment in the Portuguese educational system. This study sought to investigate the extent to which special education teams reported relationships between Body Functions, Activities and Participation, and Environmental Factors in Individualized Education Programmes for students with additional support needs and what types of relations were mostly described.

Materials and methods: Using content analysis, 176 Individualized Education Programmes were examined. A coding scheme based on the International Classification of Functioning, Disability and Health was developed to categorize and quantify code-relations.

Results and conclusions: Code-relations consisted in $6.1 \%$ out of the total of meaning units found in textual segments concerning assessment and intervention processes. Code-relations were chiefly focused on mental functions, learning and applying knowledge, and products and technology. Intervention plans were predominantly presented as separate lists of goals and strategies, focusing Activities and Participation (67.8\%), Body Functions (16.1\%) and Environmental Factors (16.2\%). Within the reduced amount of contents in which there was a match between goals and strategies, only $8.2 \%$ were directly connected with assessment data. Recommendations are made for the implementation of an interactive approach when using the International Classification of Functioning, Disability and Health in educational contexts.
\end{abstract}

$\square$ IMPLICATIONS FOR REHABILITATION

- The adoption of the International Classification of Functioning, Disability and Health in the educational context goes beyond the use of a universal language including, as well, the potential to foster a multidimensional and comprehensive approach to students' needs.

- Professionals' approach in special needs assessment is often partial and segmented, suggesting a narrow understanding of the relationships between body functions, activities and participation, and environmental factors.

- Our findings support the need for an expanded focus on person-environment interactions, considering students' participation in different domains of life - besides learning - as well as the impact of environmental barriers over students' participation;

- Training programmes centred on a biopsychosocial understanding of human functioning, the establishment of a transdisciplinary collaborative culture and the use of dynamic assessment tools may equip professionals with appropriate conditions to use the International Classification of Functioning, Disability and Health within an interactive perspective.

The Convention on the Rights of Persons with Disabilities [1] advocates that the fit between environmental demands and individuals' characteristics is a fundamental requirement for ensuring the equitable participation of all students in regular schools: "effective individualized support measures are provided in
KEYWORDS

Biopsychosocial perspective ICF-CY; IEP; participation; inclusion; students with additional supports needs environments that maximize academic and social development, consistent with the goal of full inclusion" (article 24). Accordingly, current international efforts in special needs education are being developed to refine assessment, eligibility and intervention procedures aligned with a multidimensional contextsensitive approach [2-5]. 

Traditionally, the identification of students for special education services was framed by a model focused on categorizing individuals' impairments or diseases. Criticisms to this rationale converge primarily on its one-dimensionality that locates problems solely within the individual and takes the "standards of human normalcy" as orienting principles to decide about what is recommended and prescribed for each student with additional support needs [6]. As summarized by Florian et al. [7] such categorical systems: "do not recognize the complexity of human differences; unnecessarily stigmatize children, and do not always benefit the individuals who are classified" (p.36). The change of focus from a one-dimensional to a multidimensional view of special education needs has been claimed by several practitioners and researchers [8-10]. According to such perspective, emphasis should be put as much on meeting the requirements for changes in the environment as on offering specialised services to particular students [4]. As argued by Florian and McLaugthin [10], the recognition of personal and environmental characteristics implicated in human functioning would ground decisions for individualized support planning, encompassing relevant information for curriculum and programming purposes. Such expectations are supported by evidence of an increased compatibility between assessment and intervention processes with the use of a multidimensional approach [11]. Acknowledging the restricted value of categorical disability classifications, the current Portuguese law on Special Education [12] replaced a system based on medical diagnosis of disabilities and impairments by an approach built on descriptions of students' functioning profiles with reference to the International Classification of Functioning, Disability and Health - version for children and youth (ICF-CY) [13-15]. The procedure for implementing additional supports (Figure 1) entails a referral process to school principals, stating concerns about students' difficulties that may require specialised educational measures. An initial evaluation takes, then, place to decide whether a specialized assessment is justified or not. Once justified, a specialized assessment is conducted by an interdisciplinary team composed by experts from different fields (e.g., psychologists, speech therapists, physiotherapists) together with parents and regular and special education teachers. The ICF-CY is used as a reference framework to plan the assessment - i.e., for identifying individual and contextual variables in need to be assessed - and to describe the assess ment results within a functioning profile. Such profile embodies the description of students' participation according to his/her individual characteristics and environmental circumstances [15] Eligibility is based on criteria defined by the Portuguese law [12], which states that students entitled for special education services are those who demonstrate: “( ... ) significant limitations in terms of activities and participation in one or more areas of life, due to structural and functional permanent changes resulting in continued difficulties in communication, learning, mobility, autonomy, interpersonal relationships and social participation" (article 1 , point 1). Once a student meets the eligibility criteria, an IEP is designed, planning the required accommodations and modifications for his/her successful participation in learning activities.

\section{ICF-CY framework and taxonomy}

Published in 2001 by the World Health Organization (WHO) [13], and adapted for children and youth in 2007 [14], the ICF-CY offers "a common language and a universal standard to classify components of functioning and disability" [16,p.603]. The ICF-CY is a comprehensive classification that allows a detailed description of

\section{$1^{\text {st }}$ Step: Referral}

Initiated by parents, teachers, or other educational professionals, when there is a suspicion of additional support needs.

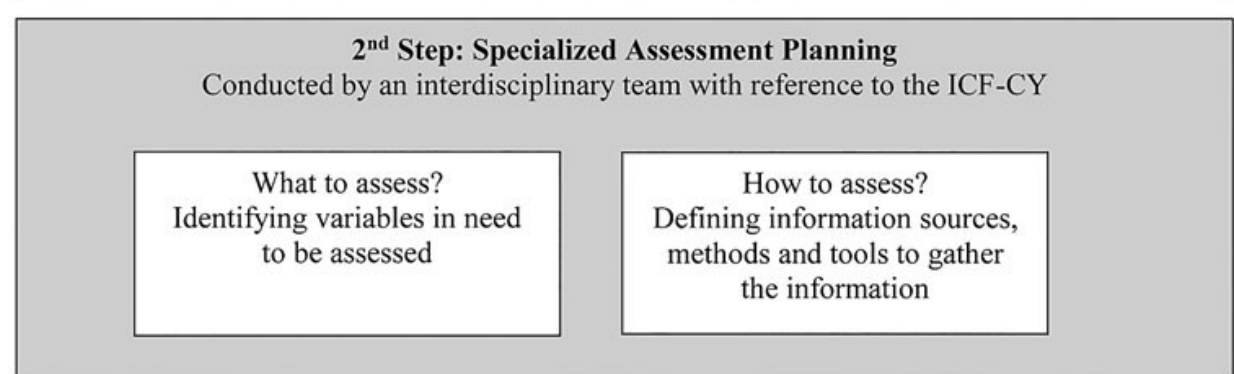

$3^{\text {rd }}$ Step: Data Collection

$4^{\text {th }}$ Step: Description of the Functioning Profile

Using the ICF-CY framework to characterize student's Activities and Participation as a result of the interaction between Body Functions and Structures and the Environmental Factors.

\begin{tabular}{|c|c|}
\hline \multicolumn{1}{|c|}{$\mathbf{5}^{\text {th }}$ Step: Eligibility Decision-Making and Educational Planning } \\
\begin{tabular}{|c|c|} 
Referred for common school \\
responses that may meet \\
support needs.
\end{tabular} & $\begin{array}{c}\text { Eligible } \\
\text { Design of an IEP which } \\
\text { implementation is coordinated } \\
\text { by the regular teacher }\end{array}$ \\
\hline
\end{tabular}

Figure 1. Special needs assessment and intervention planning. 
human functionality as the result of reciprocal influences between biological, personal and environmental variables. Its taxonomic structure groups a list of categories in four components: Body Functions; Body Structures; Activities and Participation; and Environmental Factors. According to the ICF-CY definition, the Body Functions component encompasses the "physiological functions of body systems (including psychological functions)", and Body Structures the "anatomical parts of the body such as organs, limbs and their components" [14,p.12]. Activities refer to the "execution of a task or action" and Participation to the "involvement in a life situation" [14,p14]. Environmental Factors "make up the physical, social and attitudinal environment in which people live and conduct their lives" [14,p.16]. An alphanumeric scheme is used, in which the letters $b, s, d$ and $e$ denote the Body Functions, Body Structures, Activities and Participation, and Environmental Factors components, respectively. These letters are followed by a numeric code indicating, within each component, the chapter and comprised categories. The categories are arranged hierarchically with increasing detail, from 2nd to, in some cases, 4th or 5th level codes (e.g., 2nd level: b167 Mental functions of language; 3rd level: b1671 Expression of language; 4th level: b16710 Expression of spoken language).

Codes are completed through the assignment of qualifiers indicating the magnitude of the problem. Since contextual variables may have a positive or negative impact on persons' functioning, proper coding requires that environmental factors are identified either as barriers or as facilitators.

Coherently with the ICF-CY conceptual model, the four components are connected by double-sided arrows in order to portray the reciprocal influences between them. In this regard, participative behaviour, for example, should be conceived within a complex interactive process involving the Body Functions/Structures, Activities and Environmental Factors components [17]. Such comprehensive view that recognizes multiple levels and directions of potential causal relationships embodies, in fact, a main revision of former models of disability $[18,19]$, namely the conceptual framework provided by the WHO in the past International Classification of Impairments, Disabilities and Handicaps [20], which describes disablement as the result of a unidirectional flow from impairment to disability and from disability to social handicap.

In education, recent contributions encouraging the use of relational patterns between ICF-CY components have been mostly relying on conceptual grounds [21,22]. Few others have been statistically exploring associations between Participation restrictions and Body Functions impairments [23] or Environmental Factors $[24,25]$. However, educational assessment and intervention processes remain largely informed by child-centred approaches focusing on children's limitations and impairments [26]. As found by SanchesFerreira et al. [27] in an analysis of Individualised Education Programmes (IEPs) quality, the description of variables influencing students' performance were very partial and segmented with low understanding of their interrelationships. Hence, as long as the understanding of students' participation is reduced to a sum of the parts, the planning and strategizing of individualised and social valid interventions will remain incipient [17]. Despite its unquestionable alignment with inclusion purposes the question remains on how to translate an interactive approach into the field of practice.

This study intends to identify and describe how acknowledged are the bidirectional relationships of the ICF-CY in special needs assessment and intervention processes documented in students' IEPs. Besides mapping ICF-CY code-relations, a critical discussion over its broadness and use for intervention purposes is also conducted.

\section{Methods}

\section{Data material and participants}

To document current relationships acknowledged by educational teams on using an ICF-CY informed approach, IEPs' contents were subjected to analysis. It was specifically considered: (i) the description of students' functioning profiles based on the assessment process; and (ii) the educational plan in which goals and strategies were defined.

After the formal authorization from the General Innovation and Curricular Development Board of the Portuguese Education Ministry, 316 clusters of schools were invited to participate in the study. These clusters were randomly selected from the existing 711 in Continental Portugal [28], considering their proportional distribution by the five Portuguese Regional Educational Boards. From the invited school clusters, only 73 participated in the study. Time constraints were among the most mentioned reasons for justifying the non-participation in the study.

An average of two to three processes was made available by each participating cluster. The analysis was then carried out over 176 IEPs. Informed consents from principals and parents were gathered to proceed with the IEPs' analysis. As requested on the invitation letter, all documents were received without identifying any student or school.

These documents were written for students with a mean age of 12 (SD年.06), ranging from 6 to 22 years old. The sample was mainly from elementary schools. The gender distribution was $59.1 \%$ boys and $40.9 \%$ girls. A wide range of medical diagnoses was found on students' individual processes, including intellectual disabilities, Down syndrome, cerebral palsy and developmental delays. The educational measures ascribed to the examined educational plans mostly included curriculum modifications to embody a highly individualized functional and social oriented programme (55.7\%). Other educational measures included curriculum accommodations (34.1\%) and support provision with no changes on regular curriculum (10.2\%). The IEPs were designed by teams that, in average, were composed by three members, commonly: the special education teacher, the regular teacher and the children's parents.

Data collection and analysis were developed between the academic years of 2014/2015 and 2015/2016.

\section{Data analysis}

IEPs were examined through content analysis using hand-coding without assistance of any specific software. All references portraying students' functioning were identified as meaning units and linked to the ICF-CY codes.

Using the procedure described in other studies [29,30], IEPs' contents were divided into small meaning units, with sizes established at the level of sentence fragments or of single words - as exemplified in Table 1.

Table 1. Example of linking meaning units to ICF-CY codes.

\begin{tabular}{lc} 
Meaning unit & $\begin{array}{c}\text { Meaningful concepts and } \\
\text { ICF-CY codes }\end{array}$ \\
\hline In the classroom does not concen- & Focusing attention (d I 60); Maintaining \\
trate his attention// maintaining & sitting position (d4 I 53); \\
the sitting position for short peri- & Psychomotor excitement (b / 470) \\
ods // demonstrating agitation/ & Teacher support (e330); Basic opera- \\
/Needs support of the teacher// to & tions (d I502) \\
execute simple sums and & \\
subtractions/ & \\
\hline
\end{tabular}

Note: Small meaning units signed with/slash signs/. 
Since functioning profiles require, by the Portuguese law, ICF-CY based descriptions, the linking process made use of manifest content analysis referring to visible and obvious contents [31]. IEPs' texts regarding the educational plan were examined through latent content analysis implying the interpretation of underlying senses of the meaning units [31]. The Cieza's linking rules [32] were applied for ascribing ICF-CY codes to the identified meaning units.

\section{The interactions coding scheme}

To identify the relationships between components - Body Functions and Structures (BF/BS), Activities and Participation (AP) and Environmental Factors (EF) - a relational discourse analysis was carried out on IEPs texts. This analysis - named by some authors as map analysis [33] - was based on mapping the inter-relations between meaningful concepts on the text.

Inter-relations were considered when propositions mentioning one component of functioning were linked to another (e.g., "With peers' support, he is able to write" [coding used by the researchers: e325 $\leftrightarrow \rightarrow \mathrm{d} 170$ ]). To map these connections, we considered Djirk [34] analytic model, considering: (i) the sentence order (e.g., "she has difficulties in staying concentrated and quiet. In the classroom, she gets worse during unstructured periods" [coding used by the researchers: e1300 $\leftrightarrow$ d160]) and (ii) the use of connectives (conjunctions, adverbs, adverbial compounds). To identify and categorize such code-relationships, the meaning units were considered at paragraph level.

By complying with the ICF-CY framework, relations between Body Functions and Activities and Participation (b $\leftarrow \rightarrow d$ ), Environmental Factors and Activities and Participation (e $\leftrightarrow \rightarrow d$ ), and Environmental Factors and Body Functions (e $\leftrightarrow \rightarrow$ b) were considered whenever meaningful units comprised codes pertaining to different components and reported a conditional relation between them.

To further examine the nature of the influences between codes, a distinction was made regarding the positive or negative nature of the reported conditional relationship. Positive interactions were considered when conditional relationships were described as prompting students' functioning (e.g., "the reinforcement by the teacher supported students' confidence"). Negative interactions entailed conditional relationships hindering students' functioning (e.g., "memory impairments are restraining students' performance on reading") (Table 2).

Concerning the use of the reported code-relations on the assessment and the intervention process, the number of relations identified on educational plans that entailed similar codes to those on the assessment was counted. Similarity was considered when ICF-CY codes entailed in the relations were both composed by the same first three digits (e.g., "she has difficulties performing math operations, without having concretizing materials" [d1500 01]; "Goal: promote student performance on math oper- ations" [d1502]; "Strategies: making available and demonstrating the use of concrete materials to support the counting" [e1301 d1501]). By using (4) similarity criterion, the congruence coefficient was calculated as suggested in the study of Silveira-

Maia, Lopes-dos-Santos and Sanches-Ferreira [11]:

$$
\mathrm{P} \quad \text { Congruence coefficient } 1 / 4 \overline{\mathrm{P}_{C i}} \text {; }
$$

where Sc represents the number of similar code felations observed between assessment and intervention, and $\mathrm{Ci}$ the total number of code-relations mentioned on intervention.

\section{Trustworthiness}

To assess the inter-coder reliability, a second coder worked independently on a set of 60 IEPs, $34 \%$ of the total sample. Both coders had more than 8 years of experience on special needs assessment and on the use of the ICF, with extensive involvement on ICF-CY focused research projects and training programmes. The coders received formal training on the ICF conceptual framework and taxonomy. Disagreements in the categorization of the meaning units were resolved in debriefing sessions. The mean of Cohen's kappa coefficients for the ICF-CY linked codes was of 0.78 and of 0.68 for the identified relationships between ICF-CY components, embodying good reliability according to Cicchetti [35] criteria.

The interactions coding scheme and the overall techniques of content analysis used in the study were also discussed and verified in international meetings and research seminars with other

\begin{tabular}{|c|c|c|c|}
\hline Type of code-relations & Code-relations nature & Content & Example of meaning unit and coding used \\
\hline \multirow[t]{2}{*}{$\mathrm{BF} / \mathrm{BS} \& \mathrm{AP} b \leftarrow \rightarrow d$} & Negative & BF with negative influence on $A P$ & $\begin{array}{l}\text { / She has difficulties with speaking due to her impairments on } \\
\text { articulation functions/ (b320 } \rightarrow \text { d330) / The restriction of her } \\
\text { participation on educational activities does not support the devel- } \\
\text { opment of abstraction/ (d820 } \rightarrow \text { b1640) }\end{array}$ \\
\hline & Positive & BF with positive influence on AP & $\begin{array}{l}\text { / She has good visual perception which supports the good recogni- } \\
\text { tion of words/ (b1561 } \rightarrow \text { d1400) / Her good performance with } \\
\text { reading has been a good opportunity stimulating her attention/ } \\
\text { (d166 } \rightarrow \text { b140) }\end{array}$ \\
\hline \multirow[t]{2}{*}{$\mathrm{EF} \& \mathrm{BF} / \mathrm{BSb} \leftrightarrow \rightarrow \mathrm{e}$} & Negative & EF with negative influence on BF & $\begin{array}{l}\text { / His parent have not been giving support to him. His confidence } \\
\text { has been decreasing /(e310 } \rightarrow \text { b1266) / As a sequence of his } \\
\text { unfriendly behaviour, peers are not supporting him/ (b1261 } \\
\leftrightarrow \rightarrow \text { e325) }\end{array}$ \\
\hline & Positive & EF with positive influence on BF & $\begin{array}{l}\text { / His medication has been decreasing his agitation / (e1101 } \mathbf{-} \rightarrow \\
\text { b1470) / His persistence solving problems has been instigating } \\
\text { the teacher to provide him with even more emotional support/ } \\
\text { (b1254 } \rightarrow \rightarrow \text { e330) }\end{array}$ \\
\hline \multirow[t]{2}{*}{$E F \& A P d \leftarrow \rightarrow e$} & Negative & EF with negative influence on $\mathrm{AP}$ & $\begin{array}{l}\text { The background noise on the classroom seems to disturb the con- } \\
\text { clusion of tasks/ (e2501 } \rightarrow \text { d2104) / Her difficulty to accept } \\
\text { criticisms seems to be motivating the disregard from other profes- } \\
\text { sionals/ (d7103 } \rightarrow \text { e } 360 \text { ) }\end{array}$ \\
\hline & Positive & EF with positive influence on AP & $\begin{array}{l}\text { / She reads words with associated images / (e1301 } \rightarrow \rightarrow \mathrm{d} 1400) / \\
\text { Her great sympathy when dealing with others was halfway for } \\
\text { peers' positive attitudes/ (d7100 } \rightarrow \rightarrow \text { e425) }\end{array}$ \\
\hline
\end{tabular}
researchers involved in ICF focused research projects.

Table 2. Coding scheme for mapping code-relations.

Note: Meaning units signed with/slash signs/. 
Table 3. Total references (mean; standard deviation) to functioning codes and code-relations in each of the examined parts: assessment - functioning profile and intervention - educational plan.

\begin{tabular}{|c|c|c|}
\hline Section & $\begin{array}{l}\text { References to functioning codes } \\
\qquad n(M ; S D)\end{array}$ & $\begin{array}{l}\text { References to code-relations } \\
\qquad n(M ; S D)\end{array}$ \\
\hline \multicolumn{3}{|c|}{ Assessment - functioning profile } \\
\hline $\begin{array}{l}\text { Total } \\
\text { Detaileda }\end{array}$ & $\begin{array}{l}7044(40.02 ; 18.54) \\
b-2134(12.13 ; 6.3) \\
d-3689(20.96 ; 12.36) \\
e-1221(6.94 ; 4.58)\end{array}$ & $\begin{array}{l}710(4.03 ; 3.69) \\
b \underset{ }{\leftarrow} \rightarrow-223(1.27 ; 1.64) \\
b \underset{e}{\leftrightarrow} \rightarrow 53(.30 ; .67) \\
d \leftrightarrow \rightarrow e-439(2.49 ; 2.72)\end{array}$ \\
\hline \multicolumn{3}{|c|}{ Intervention - educational plan } \\
\hline $\begin{array}{l}\text { Total } \\
\text { Detaileda }\end{array}$ & $\begin{array}{l}10756(61.11 ; 41.12) \\
b-1732(9.84 ; 10.69) \\
d-7287(41.40 ; 30.54) \\
e-1737(9.87 ; 8.28)\end{array}$ & $\begin{array}{l}377(2.14 ; 2.24) \\
b \underset{ }{\leftarrow} \rightarrow-6(.03 ; .24) \\
b \underset{e}{\leftarrow} \rightarrow-66(.38 ; .67) \\
d \leftrightarrow \rightarrow e-300(1.70 ; 1.89)\end{array}$ \\
\hline
\end{tabular}

${ }^{\mathrm{a}}$ There were not found meaningful concepts regarding Body Structures.

Results

\section{Broadness of the interactions}

From the analysis of 176 IEPs, 17.800 meaningful concepts were identified and linked to ICF-CY codes: 7.044 in the description of functioning profiles and 10.756 in the educational plans.

Starting with the distribution of the meaningful concepts by the ICF-CY components, as shown in Table 3, a mean of around 40 codes was found within each functioning profile: 21 dedicated to the students' performance on Activities and Participation, 12 on Body Functions and 7 on Environmental Factors. A mean of 61 codes was found in each educational plan, with prominence of codes inscribed in the Activities and Participation component (a mean of 41), followed by Environmental Factors and Body Functions - both with a mean of 10 codes. Overall, on special needs assessment and intervention processes, the emphasis was placed in the Activities and Participation component (61.7\% of the total references), followed by Body Functions (21.7\%). Environmental Factors was the least mentioned component (16.6\%).

From the total of the identified meaningful concepts, $6.1 \%$ reported code-relations. Concerning, specifically, the functioning profiles, about $10 \%$ of the meaningful concepts reported a coderelation, with a mean occurrence of 4.03 per profile. Within the intervention, around $3-4 \%$ of the references documented a coderelation, with a mean of 2.14 per educational plan.

Within the universe of the identified code relations $\left(n \frac{1}{4} 1087\right)$, most of them $(67.9 \% ; n / 4739)$ reported a conditional relationship between students' performance on Activities and Participation and the Environmental Factors, embodying: $79.6 \%$ of the coderelations found in the intervention plans and $61.8 \%$ in the functioning profiles. The reciprocal influence between Body Functions and Activities and Participation also embodied a substantial part of the code-relations documented on the functioning profiles (31.4\%).

Figure 2 presents the relations reported on functioning profiles, organized at the domain level. To make the analysis clearer, the picture presents only the most frequent connections - those registered in, at least, 10 cases and whose counting units embodied more than $1.3 \%$ of the total code-relations.

Within the relations described throughout the functioning profiles, the connection between mental functions and products and technology with learning and applying knowledge assumed prominence. These connections were followed by relations between selfcare, major life areas and learning and applying knowledge with support and relationships. Interrelations between Body Functions and Environmental Factors mainly reported an associ- ation between mental functions with Products and Technology and with Support and Relationships.
Proceeding with a detailed analysis of such relational dyads (please see Table S1 on Supplementary material), it was observed that the connection between Mental Functions and Learning and Applying Knowledge reported mostly a negative impact of such impairments on the students' performance. Actually, the $b \leftrightarrow \rightarrow d$ (Body Functions - Activities and Participation) type of code-relation was mainly characterized by a one-direction and negative nature. Inversely, the association between the environment and the activities and participation was expressed mainly in positive terms, specifically documenting the importance extent of products and technology in supporting learning and applying knowledge. The same tendency was found on the connection between Environmental Factors and Body Functions, expressing a supportive role of products and technology, as well as, of support and relationships over the mental functions.

At the intervention level, Figure 3 maps the relations found in educational plans. As previously, the picture presents only the most frequent connections that were registered in, at least, 10 cases and whose counting units embodied more than $3.8 \%$ of the total code-relations.

The goals defined on learning, executing tasks and communication were paired with strategies inscribed on products and technology. Supports and relationships was another environmental strategy linked to goals stated on the learning, on executing tasks, on self-care and on major life areas domains.

Also, goals stated on Body Functions component, specifically on Mental Functions domain, were paired with strategies related to products and technology and to support and relationships.

All of the code-relations identified in the intervention were expressed in positive terms stating a supportive role of Environmental Factors over students' Activities and Participation or over students' Body Functions (please see Table S2 on Supplementary material). Residually, there were also mentions to a positive effect of Body Functions over students' performance, and of students' involvement on Activities and Participation over the development of Body Functions.

\section{Use of the interactions for intervention planning}

Regarding the conversion of relations described in the functioning profiles into the matching between intervention goals and strategies, only 31 code-relations in the educational plans were similar to the ones described in the assessment $(8.2 \%$ of the code-relations in the educational plan). Similar code-relations consisted in environmental factors and activities and participation dyads.

\section{Discussion}

Our study findings showed an underrepresentation of descriptions focused on the intersection of ICF-CY components (i.e., Body 


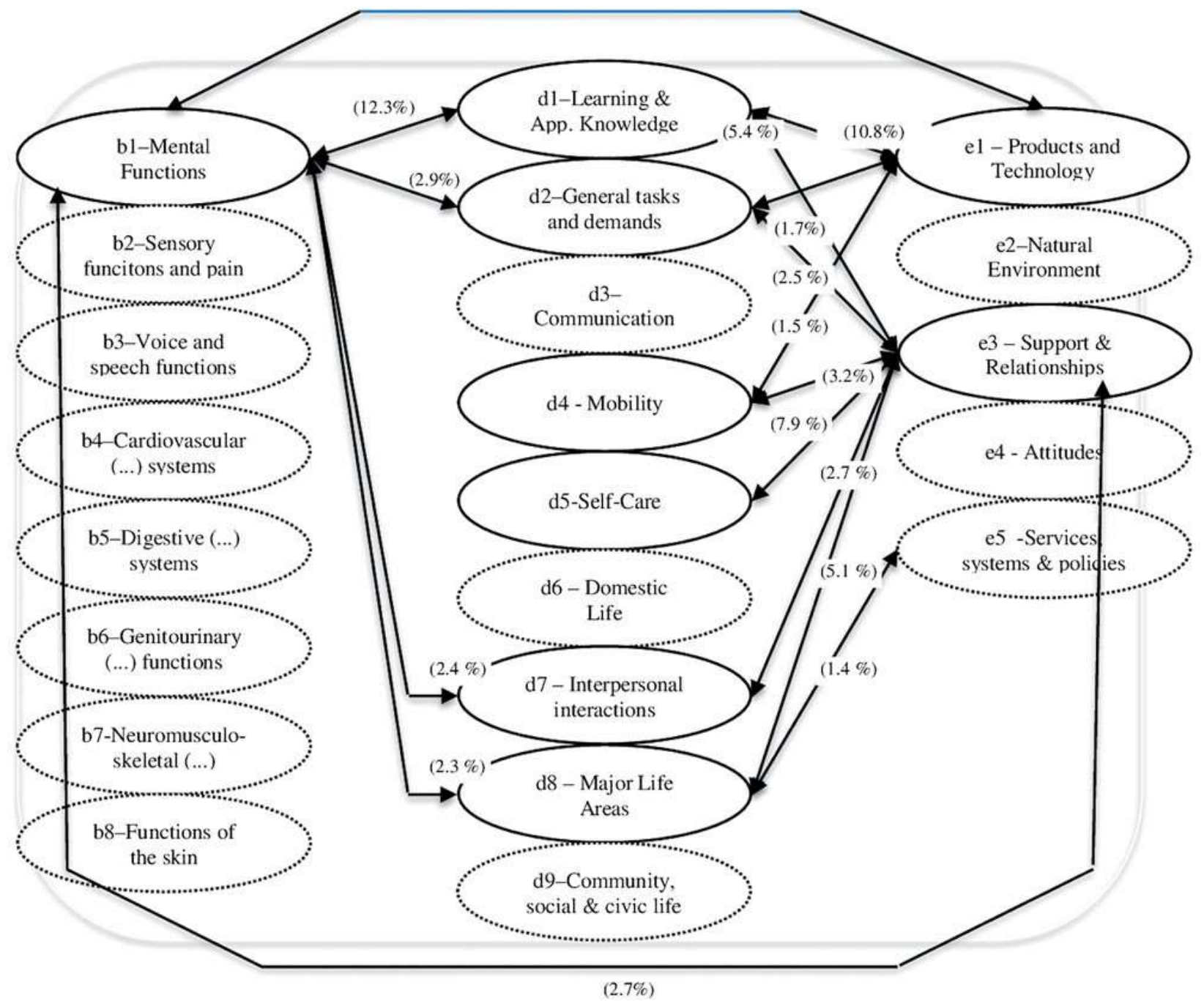

Figure 2. Most frequent code-relations: percentage of their representation within the total of relations on the functioning profiles.

Functions/Structures, Activities and Participation, and Environmental Factors), embodying only $6 \%$ of the meaning units found in assessment and intervention texts. The prevalence of segmented descriptions of Body Functions, Activities and Participation, and Environmental Factors seems to suggest an incipient understanding of the ICF-CY multidirectional relationships. Similar results have already been found in other studies $[11,27]$, which report that components' coding is mostly made as separate topics, not informing how do they relate with each other. This limited use of an interactive approach underlines that teacher professional development programmes should pay particular attention to the expansion and deepening of professionals' knowledge on student-environment interaction patterns [25-27].

However, it is worth noting that, when compared with the intervention accounts, we found a higher percentage of code-relations in assessment texts. Such finding suggests that the ICF-CY usage favours in itself a comprehensive understanding of students' participation.

Code-relations found in assessment and intervention texts were mostly focused on links between mental functions, learning and applying knowledge, and products and technology. Specifically, some of the examined functioning profiles described negative influences of mental functions' impairments and positive impacts of products and technology on students' learning. Among these kinds of descriptions - in which educational teams have explicitly acknowledged existing relations between components there was a scarce proportion of intervention strategies aligned with the previously assessed information. Indeed, from the total number of code-relations found in the intervention plans only $8 \%$ were similar (i.e., composed by the same codes) to the ones identified in the assessment. Although research evidence has shown that the ICF-CY use seems to increase the congruence between assessment and intervention data (e.g., by supporting more effective problem-solving approaches) [11], a chronic disconnection between what is assessed and what is implemented as support

[36] remains still visible in current educational practices.

In addition to the shortcomings regarding how the ICF-CY framework is being transposed into the IEPs, further considerations should be made concerning the functional and contextual domains acknowledged in those documents. Since code-relations were mostly confined to the areas of learning and knowledge application, it seems relevant to highlight the need of a wider and comprehensive description of influences on other participation domains (e.g., mobility, self-care, home living, interpersonal 
$(6.4 \%)$

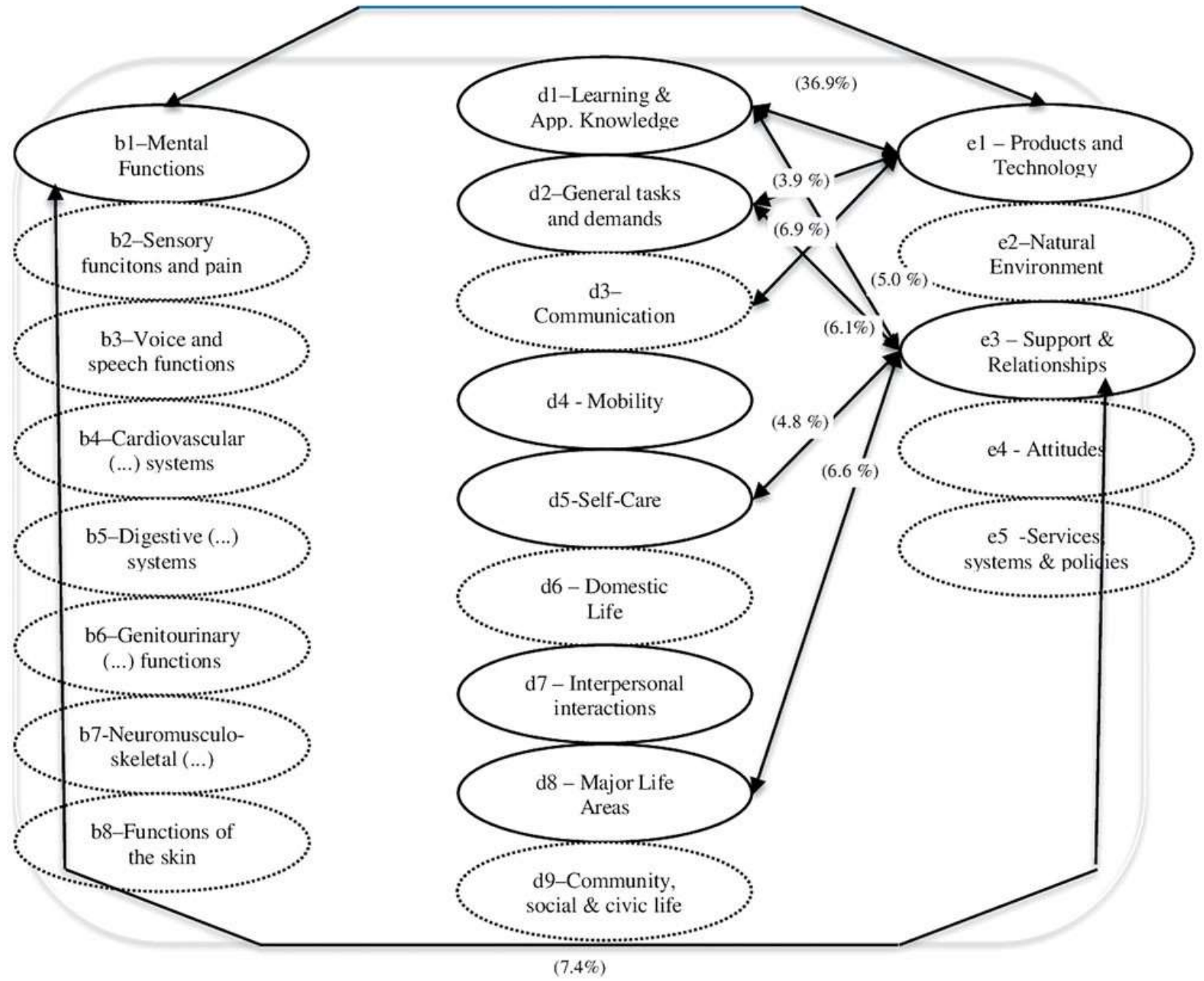

Figure 3. Most frequent code-relations: percentage of their representation within the total of relations on the educational plans.

relationships, civic and community living). This wider comprehensiveness will allow both the establishment of educational goals and the design of highly individualized functional programmes more suitable for promoting the full potential of students with disabilities [1,12]. Moreover, the near absence of references to negative effects of environmental barriers on students' functioning, as well as, to positive impacts of Body Functions on students' performance, requires attention in terms of removing environmental barriers for included students [37] and of attending to their strengths (i.e., portraying what students can do, rather than what they cannot do) [38]. As reported in other studies [27,37], a critical analysis over environmental factors - uncovering optimal conditions to support students' participation - and the implementation of a strength-based approach remains postponed by the prominence of impairment-based views.

The need of expanding an interactive approach when using the ICF-CY in educational contexts, and the acknowledgement that the ICF-CY usage goes beyond the use of an universal language to entail a comprehensive way of approaching students' needs, future supportive factors should be acknowledged at three levels:

1. Training: stating - from the gap between ICF-CY conceptual

framework and many current special education approaches

- the need of designing and implementing ICF-CY training programmes that go beyond the mere coding of skills to acknowledge the planning of biopsychosocial assessments and interventions. Specifically, it seems to be needed a deeper focus on: (i) dynamic assessment, describing students' participation with and without supports (specifying what, how, where and by whom supports are being implemented) [26]; (ii) problem-solving reasoning, prompting the connection between assessment results and intervention planning [27]; (iii) strength-based approach, bridging what students do and what they could do with appropriate supports $[38,39]$.

2. Collaboration: assuming the development of a transdisciplinary collaborative culture, a required advance to enable the capturing of mutual influences between the ICF-CY components [40].

3. Research: by developing (i) tools focused on assessing students' performance paired with specific environmental conditions/supports [26]; (ii) case examples and support materials guiding a comprehensive integration of data, opposed to templates inducing a separate entry to each ICF$\mathrm{CY}$ component [11]; (iii) software platforms providing an intelligent assistance for connecting assessment data and intervention goals and strategies [41]. 
Limitations should be recognized to this study, namely by not analysing variables with possible influence on the implementation of an interactive perspective, like the diversity and experience of professionals including the teams, the time dedicated to each assessment and intervention plan, the enrolment (or not) on ICFCY training, or the adopted type and diversity of assessment tools. There was also a non-negligible number of schools that although accepting to participate in the study - did not provide complete IEPs.

Future studies may intend to achieve a more holistic analysis, exploring how the implementation of an interactive perspective is influenced by variables posed at team and assessment procedures level. Also, the analysis of code-qualifiers and their covariation along time would add valuable information on how the three ICF$\mathrm{CY}$ components relate to each other.

\section{Disclosure statement}

No potential conflict of interest was reported by the authors.

\section{ORCID}

Manuela Sanches-Ferreira (D) http://orcid.org/0000-0002-4693-3928

\section{References}

[1] UN - United Nations. Convention on the rights of persons with disabilities. New York: United Nations Division for Social Policy and Development; 2006.

[2] De Polo G, Pradal M, Bortolot S, et al. Children with disability at school: the application of ICF-CY in the Veneto region. Disabil Rehabil. 2009;31:S67-S73.

[3] Francescutti C, Gongolo F, Simoncello A, et al. Description of the person-environment interaction: methodological issues and empirical results of an Italian large-scale disability assessment study using an ICF-based protocol. BMC Public Health. 2011;11:S11.

[4] Hollenweger J. Development of an ICF-based eligibility procedure for education in Switzerland. BMC Public Health. 2011;11:S7-S8.

[5] Tokunaga A. Trends and perspective of the use of International Classification of Functioning, Disability and Health (ICF) on special needs education in Japan. J Special Educ Asia Pacific. 2006;2:17-30.

[6] Reindal S. What is the purpose? Reflections on inclusion and special education from a capability perspective. Eur $J$ Special Needs Educ. 2010;25:1-12.

[7] Florian L, Hollenweger J, Simeonsson R, et al. Cross-cultural perspectives on the classification of children with disabilities. J Spec Educ. 2006;40:36-45.

[8] Hollenweger J. Cross-national comparisons of special education classification systems. In: Florian L, McLaughlin M, editors. Disability classification in education: issues and perspectives. CA: Corwin Press; 2008. p.11-27.

[9] Simeonsson R, Simeonsson N, Hollenweger J. International Classification of Functioning, Disability and Health for children and youth: a $M$ language for special education. In: Florian L, McLaughlin M, editors. Disability classification in education: issues and perspectives. California: Corwin Press; 2008. p. 207-217.
[10] Florian L, McLaughlin MJ. Disability classification in education: issues and perspectives. Thousand Oaks (CA): Corwin Press; 2008.

[11] Silveira-Maia M, Lopes-dos-Santos $P$, Sanches-Ferreira $M$. How the use of the International Classification of Functioning, Disability and Health for children and youth changed the individualized education programs in Portugal. Int J Inclusive Educ. 2017;21:573-583.

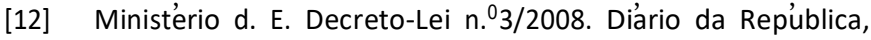
7 de Janeiro. 2008.

[13] Capucha L, Pereira F, Crespo A, et al. Educação especial manual de apoio a pratica. Lisboa: direcção-geral de inovação e de desenvolvimento curricular; 2008.

[14] World Health Organization. International Classification of Functioning, Disability and Health. Geneva: World Health Organization; 2001.

[15] World Health Organization. International Classification of Functioning, Disability and Health - version for children and youth. Geneva: World Health Organization; 2007.

[16] Simeonsson R, Leonardi M, Lollar D, et al. Applying the International Classification of Functioning, Disability and Health (ICF) to measure childhood disability. Disabil Rehabil. 2003;25:602-610.

[17] Mallinson T, Hammel J. Measurement of participation: intersecting person, task, and environment. Arch Phys Med Rehabil. 2010;91:S29-S33.

[18] Masala C, Petretto D. From disablement to enablement: conceptual models of disability in the 20th century. Disabil Rehabil. 2008;30:1233-1244.

[19] Noreau L, Boschen K. Intersection of participation and environmental factors: a complex interactive process. Arch Phys Med Rehabil. 2010;91:S44-S53.

[20] World Health Organization. International classification of impairments, disabilities and handicaps: a manual of classification relating to the consequences of disease. Geneva: World Health Organization; 1980.

[21] Maxwell G, Alves I, Granlund M. Participation and environmental aspects in education and the ICF and the ICF-CY: findings from a systematic literature review. Dev Neurorehabil. 2012;15:63-78.

[22] Granlund M. Participation-challenges in conceptualization, measurement and intervention. Child Care Health Dev. 2013;39:470-473.

[23] Schenker R, Coster W, Parush S. Neuroimpairments, activity performance, and participation in children with cerebral palsy mainstreamed in elementary schools. Developmental Med Child Neurol. 2005;47:808-814.

[24] Eriksson L. The relationship between school environment and participation in students with disabilities. Pediatric Rehabil. 2005;8:130-139.

[25] Silveira-Maia $M$, Lopes-dos-Santos $P$, Sanches-Ferreira $M$, et al. Dimensões ambientais e produtos e tecnologias influentes na participação e inclusão de alunos com incapacidade. Educatio. 2017;35:105-128.

[26] Lebeer J, Partanen P, Candeias A. The Need for a more dynamic and ecological assessment of children experiencing barriers to learning to move towards inclusive education: a summary of results of the daffodil project. Transylvanian J Psychol. 2013;Special Issue:175-205.

[27] Sanches-Ferreira M, Lopes-dos-Santos P, Alves S, et al. Dynamic functioning profiles using the ICF-CY: outcomes of a teacher training program applied in Portugal. Int $J$ Inclusive Educ. 2017;22:734-750. 
[28] Direção Geral de Estatisticas da Educação e da Ciencia Estatisticas Globais: educação pré-escolar, Ensino básico e Secundario. Direção Geral de Estatisticas da Educação e da Ciencia; 2014.

[29] Klang Ibragimova N, Pless $M$, Adolfsson $M$, et al. Using content analysis to link texts on assessment and intervention to the International Classification of Functioning, Disability and Health - version for children and youth (ICF-CY). J Rehabil Med. 2011;43:728-733.

[30] Darcy L, Enskar K, Granlund M, et al. Health and functioning in the everyday lives of young children with cancer: documenting with the International Classification of Functioning, Disability and Health - children and youth (ICFCY). Child Care Health Dev. 2015;41:475-482.

[31] Graneheim U, Lundman B. Qualitative content analysis in nursing research: concepts, procedures and measures to achietrustworthiness. Nurse Educ Today. 2004;24:105-112.

[32] Cieza A, Geyh S, Chatterji S, et al. ICF linking rules: an update based on lessons learned. J Rehabil Med. 2005; 37:212-218.

[33] Carley K. Coding choices for textual analysis: a comparison of content analysis and map analysis. Sociological Methodol. 1993;23:75-126.

[34] Dijk T. Semantic discourse analysis. Handbook of discourse analysis. London: Academic Press; 1985.

[35] Cicchetti D. Guidelines, criteria, and rules of thumb for evaluating normed and standardized assessment instruments in psychology. Psychological Assessment. 1994; 6:284-290.

[36] Drasgow E, Yell M, Robinson T. Developing legally and educationally appropriate IEPs. Remedial Special Educ. 2001;22:359-373.

[37] Maxwell G, Granlund M. How are conditions for participation expressed in education policy documents? A review of documents in Scotland and Sweden. Eur J Special Needs Educ. 2011;26:251-272.

[38] Wehemeyer M, Shogren K, Singh N, et al. Strengths-based approaches to intellectual and developmental disabilities. In: Shogren K, Wehmeyer M, Singh N, editors. Handbook of positive psychology in intellectual and developmental disabilities. New York (NY): Springer Series on Child and FamilyStudies; 2017. p. 13-21.

[39] Thompson J, Wehmeyer M, Hughes C. Mind the gap! Intellectual disability as individual-environment fit: implications for students, teachers, and schools. Exceptionality: A Special Educ J. 2010;18:168-181.

[40] Sanches-Ferreira M, Lopes-dos-Santos P, Alves S, et al. How individualized are the Individualised Education Programmes (IEPs): an analysis of the contents and quality of the IEPS goals. Eur J Special Needs Educ. 2013;28:507-520.

[41] Arsenopoulou V. Implementation of the ICF-CY in an early intervention program. Paper presented at 1st international conference on research in education; 2017 July 19-21; Porto, PT. 